\title{
腹腔鏡下外科手術における術具操作逆運動問題の一提案 (立ち姿勢形の中間システム)
}

\author{
A Proposal for the Reverse Motion Problem on Laparoscopic Surgical Operation
}

(Middle system by standing pose)

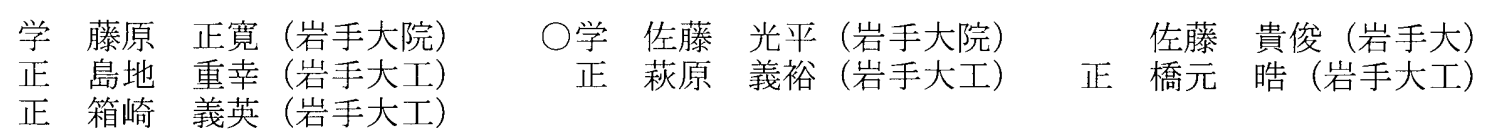

Masahiro FUJIWARA, Kouhei SATO, TAKATOSI SATO, Graduate school of Iwate University Takatoshi SATO, Iwate University Shigeyuki SHIMACHI, Yoshihiro HAGIHARA, Akira HASHIMOTO, Yoshihide HAKOZAKI, Faculty of Engineering Iwate University

In laparoscopic surgical operation, the each ends of the forceps moves reversely to each other. The reverse motion might be a factor which makes surgeon miss-operate and causes the operation delay. This paper proposes a new device which cancels the reverse motion with pantograph mechanism on standing pose of surgeon. Authors evaluate the device by the required time for elemental surgical operations. A facility on manipulability of the instrument is searched on relation between hand motion and forceps motion in monitor. It is cleared that required time is reduced about $20 \%$ for knot working as an elemental surgical operation on the condition in which hand motion agrees with the forceps motion in monitor.

Key Words: Laparoscopic, Forceps

\section{1.緒言}

近年，急速に普及している外科手法が腹腔鏡下外科手術で ある. それは小さな穴を通して術具を挿入し, 腹腔内で処置 を行う手法である．患者にとって身体的，経済的に負担が掛 からない手法だが,術者には熟練を要する手法でもある.

熟練を要するのは腹腔鏡下外科手術の専用の術具, 内視鏡 での映像や術具の操作に問題が生じるためである.

本論文では腹腔鏡下外科手術の問題の一つである逆運動操 作を解消するシステムを開発し，外科支援装置として基本的 な手術動作を検証し, いくつかの操作条件のなかで作業時間 に与える影響の実験を行い，その結果を述べていく。

\section{2. 逆運動操作を解消するシステム}

\section{1 逆運動操作問題}

逆運動操作問題とは患者の体内側と体外側で術具操作の運 動が逆方向になる問題である. 腹部の穴が点対称な点として 作用するため挿入方向に対しては生じない。これは手術を困 難にさせる一因と考えられる. 逆運動操作問題を解消するに は, 腹部の穴に対して事前に点対称を起こす機構を用いて点 対称な運動にする必要がある。

\section{2 システム概要}

本論文で開発するシステムは点対称を起こす機構部と装置 そのものを移動させるリンク部, 操作(マスタ一部)と作動(ス レーブ部)の各装置によって構成した(図 1 参照). 点対称を起 こす機構はパンタグラフを使用する.支点を境にXの動作はX' の動作へ，Yの動作はY'になる．またパンタグラフの支点を支 えるリンクで挿入方向Z一平行移動する(図2参照).

マスター部では鉗子の自由度に応じて，把持や鉗子全体の 回転, 多自由度鉗子による折れ曲げ・先端部の回転といった 操作を可能にした。把持はてこの原理を用いて力を伝達し， 鉗子全体の回転はワイヤ駆動で回転を伝える．把持は把持リ ンクを回転することで, 歯車 1 ・2 に力が伝わり, シャフト を押し込みてこへ伝わる(図3参照). 回転は土台を回転するこ とでプーリを一緒に回転しワイヤ駆動する. 多自由度鉗子の 折れ曲げ・先端部の回転は把持リンクの一部に固定するポテ ンショメータと歯車 4 の同軸上にポテンショメータで読み取 る. 先端部の回転は直接回転させ，折れ曲げは把持リンクを 曲げることで, 歯車 3 と歯車 4 が遊星歯車のように回転し, 把持リンクが傾くことで曲げを検出する(図4参照).
スレーブ部は鉗子をはめ込み, マスター部からの操作を 鉗子に伝える. 把持力はてこによって伝達され，把持部を上 方へ引くことで把持する(図5参照). またワイヤ駆動で伝わる 力はスレーブ部全体を回転することで鉗子も回転させる．多 自由度鉗子の場合は, 先端部回転と折れ曲げのモータとポテ ンショメータでマスター部のポテンショメータの電圧值を読 み, 電圧值を一致させるフィードバックを行う.

把持力を伝えるのにてこを用いるが，図6のように配置 する. パンタグラフの関節部分にてこの作用点と力点を重な るように配置し，円弧運動に対しては十分な長さにすること で直線に近似した動さとした。また関節部分に球状のスペー サーを挟むことで運動の妨げにならないようにした。

ワイヤ駆動するためにプーリをパンタグラフの回転軸上に 配置した(図 7 参照).また，マスター部の回転軸のプーリの直 径とスレーブ部の回転軸のプーリの直径を $2 ： 1$ とした。

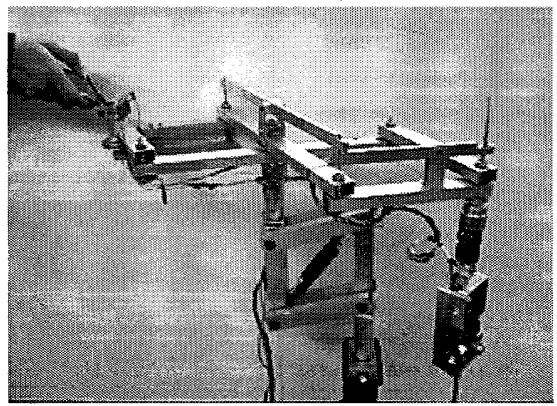

Fig. 1 Machine device with pantograph mechanism

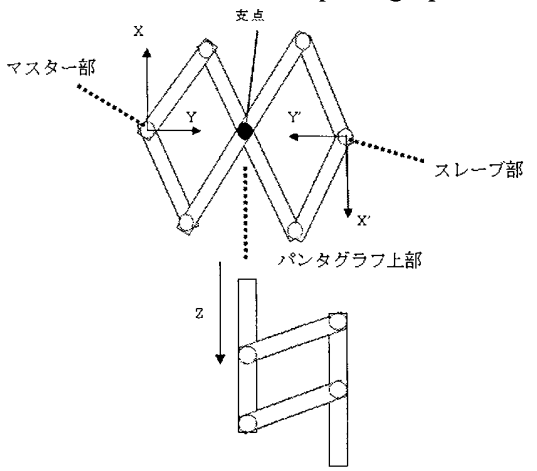

Fig.2 pantograph mechanism and parallel linkage 


\section{3. システムの仕様}

システムの可動域はパンタグラフの開閉と回転, 術具方向 への移動で定まる．パンタグラフの開閉は支点の角度が 12.5 〜 165 度変化することで, 約 $280 \mathrm{~mm}$ 可動可能である.さらに支 点を中心に回転が可能. パンタグラフの可動と鉗子の可動は 鉗子が腹部に挿入した長さに関係し，鉗子が 150 mm腹腔内挿 入した場合，鉗子の可動域は腹部の穴に対し，頂角 50 度の円 錐上を可動可能である.またベッド取り付け部はカメラの固 定で使用される球面ジョイントで，向きを可変できる(図 8 参 照)，腹腔鏡下外科手術では 95 パーセントが頂角 60 度の円錐 上[1]で手術を行っているので，十分とはいえないが，このシ ステムは術具方向を任意に変更可能なので可動範囲の不足分 は補える。

鉗子は引つ張り力で引くことで先端が開閉し把持する仕組 みになっている. システムの把持力はてこの長さをパンタグ ラフの支点から対称にし, マスター部の剪む力と把持に必要

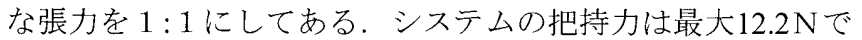
ある。また多自由度鉗子の制御はPIC16F877を使用し，ポテン ショメータとモータでフィードバック制御を行う。

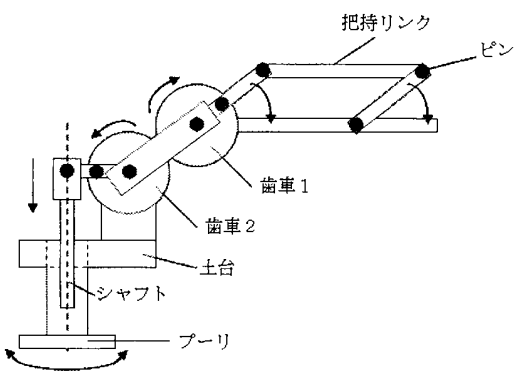

Fig, 3 Master part right side view
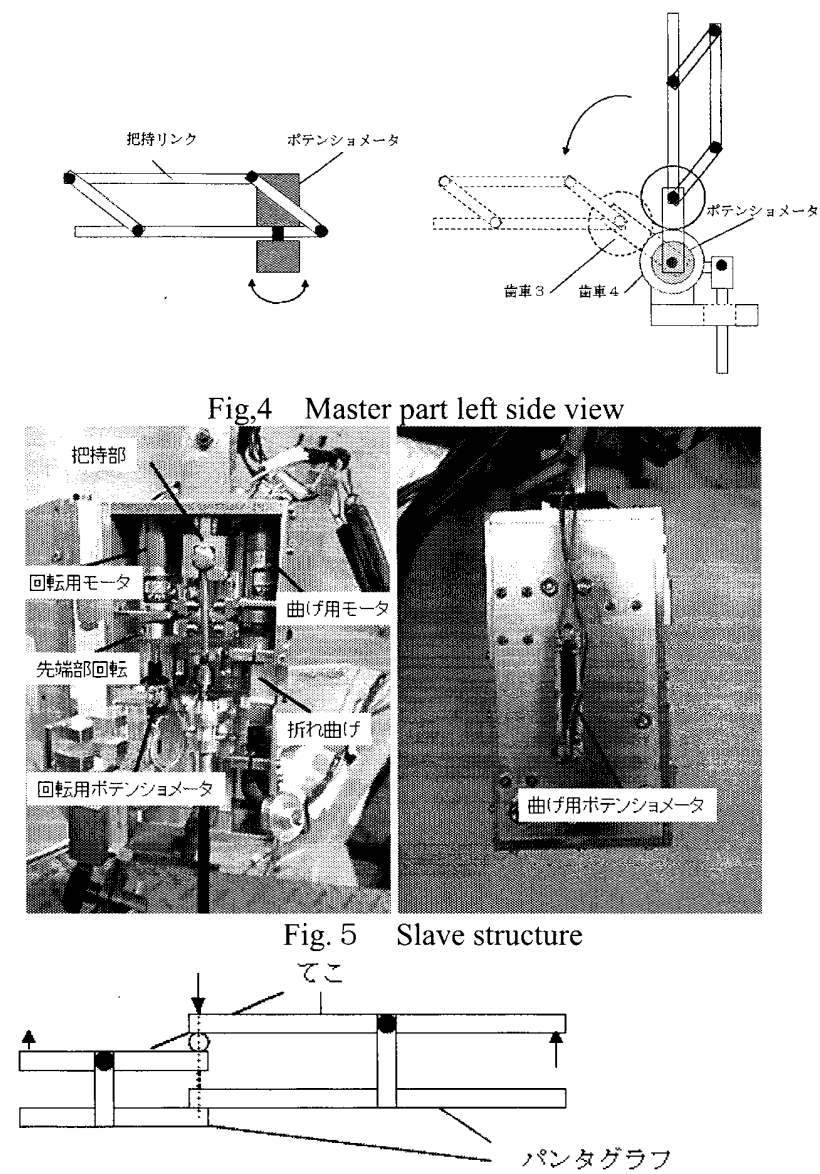

Fig.6 Arrangement of lever
鉗子先端の回転は通信遅れ 0.01 秒で 45 度までは 0.15 秒で回 転する。一方, 折れ曲げは 0.1 秒の通信遅れが生じ, 4.3 秒で 70 度まで曲がることが可能である。

\section{4. 予備実験}

\section{1 座標系の定義}

腹腔鏡下外科手術の場合, 術者はテレビモニタ内の映像を 見ながら，鉗子を操作して手術する。ここで術者の操作座標 系を操作座標（X0，Y0，Z0），鉗子で作業する座標系を作業 座標 $(\mathrm{X} 1 ， \mathrm{Y} 1 ， \mathrm{Z} 1)$ ，内視鏡によって映し出されるテレビモ 二夕内の座標系を視座標 $(X 2 ， Y 2 ， Z 2 ）$ と定義する（図 9 参 照）。術者はそれぞれ異なる座標系において, 通常の開腹手 術以上に高度な技術や熟練を要すると考えられる。

\section{2 システム環境の定莪}

システムを使用しやすい環境を実際に操作して検証した。 予備実験の結果, ベッドに対してシステムを取り付けると十 分な作業空間が得られた. 操作性を考慮して, 胸よりやや下 の高さにシステムのマスター部がくるようにした。実験で使 用する鉗子の挿入角度は作業平面に対し60度前後, ベッドに 平行な面に対し45度とする。

\section{1 実験器具}

\section{5. 実験}

実験を始めるにあたって，実験で使用する装置や道具を述 ベる。まず開発したシステム，システムに使用する鉗子（市 販鉗子にアタッチメントを取り付けたもの) (図10参照), 市販 鉗子 (先端部変更), トロカールモデル, カメラ, テレビモ ニタ，医療用針(図11参照), 医療用系，ベッドモデルを使用す る.今回，多自由度鉲子は使用しない。

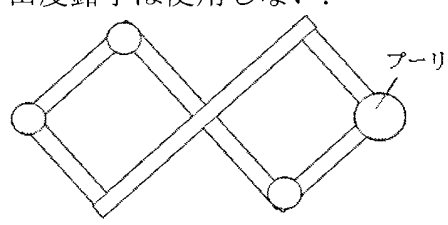

Fig. 7 Arrangement of pulley
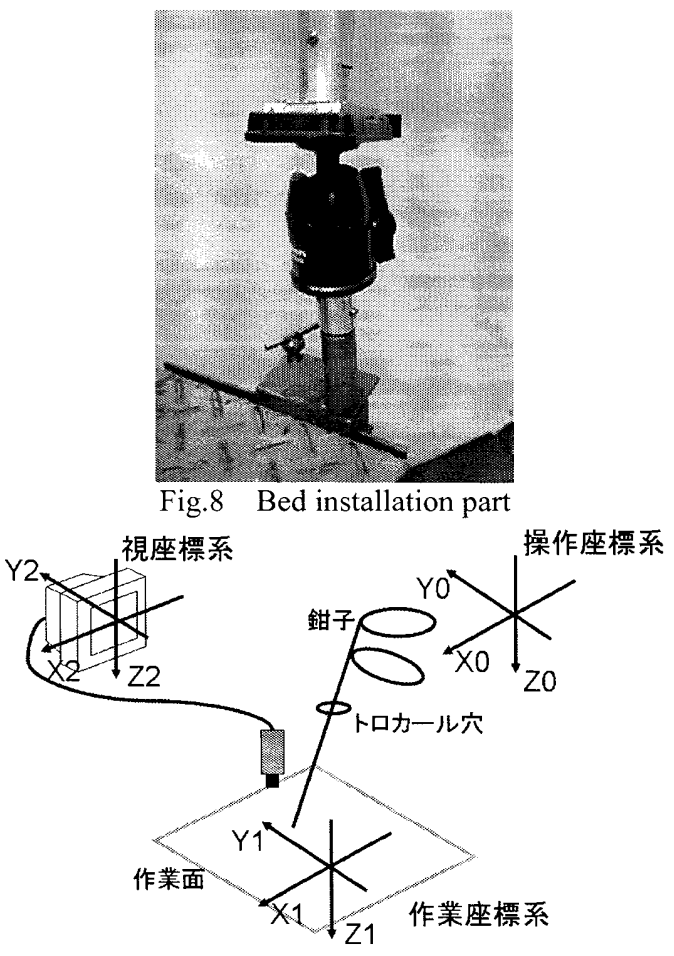

Fig. 9 Coordinate system on Laparoscopic Surgery 


\section{2 実験方法}

手術の基本動作である縫う・結ぶといら動作を手術条件で どのような変化を生じるか実験を行う．被験者は 5 または 6 人の初心者とする.使用針は KEISEI の DS 402 ナミでシス テムと普通鉗子の使用での比較を行う。手術条件は通常条件, 作業軸条件，立体視条件の3つで行う。

通常条件は実際に使用されている形式で，術者に対してテ レビモニタが正面に配置した条件となる(図 12,13 参照)，正 面にあるため操作座標と視座標が一致していない。

作業軸条件は逆運動操作の操作性が向上した操作座標と視 座標を一致した座標系を持つ(図 14，15参照)[2]. これにはテ レビモニタを足元に配置することで成立する。

立体視条件は物体を立体的に捉える条件である。こ れは 2 つのメラで物体を撮ることで,それぞれの映 像を得ることができる.さらにその映像を片目ずつ見 ることで立体視ができるのである(図 16 参照).

\section{(縫う作業)}

対称物（スポンジ）は幅 $6 \mathrm{~mm}$ と $2 \mathrm{~mm}$ のーキングをつけ る(図 17 参照)。マーキングされた対象物を縦・横・斜めに順 に固定し，あらかじめ針を持ってもらい一方向ごとに対象物 に針を刺し，抜き取るまでの時間を計測する(図 18 参照)。針 を落とすまたは針の持ち方に問題が生じた場合，計測をリセ ットして再度行う。逆運動操作の実験なので, 操作開始地点 はテレビモニタ左上地点からしてもらう。またピンセットで 対象物を押さえて縫う補助を行う。

\section{(結紮作業)}

結ぶとういう動作が逆運動操作に最も影響を受ける作業と 考え，縫合におうりる結びに要する時間を計測する．結び方は 図 19 の縫合手順の 2 の状態から始める. 対象物はマーキング のないスポンジとする。これも針を落とすまたは針の持ち方 に問題が生じた場合, 計測をリセットして再度行う。ピンセ ットでの補助動作は対象物を押さえるまたは糸を引くだけと する．実験回数は一人三回ずつ行う。

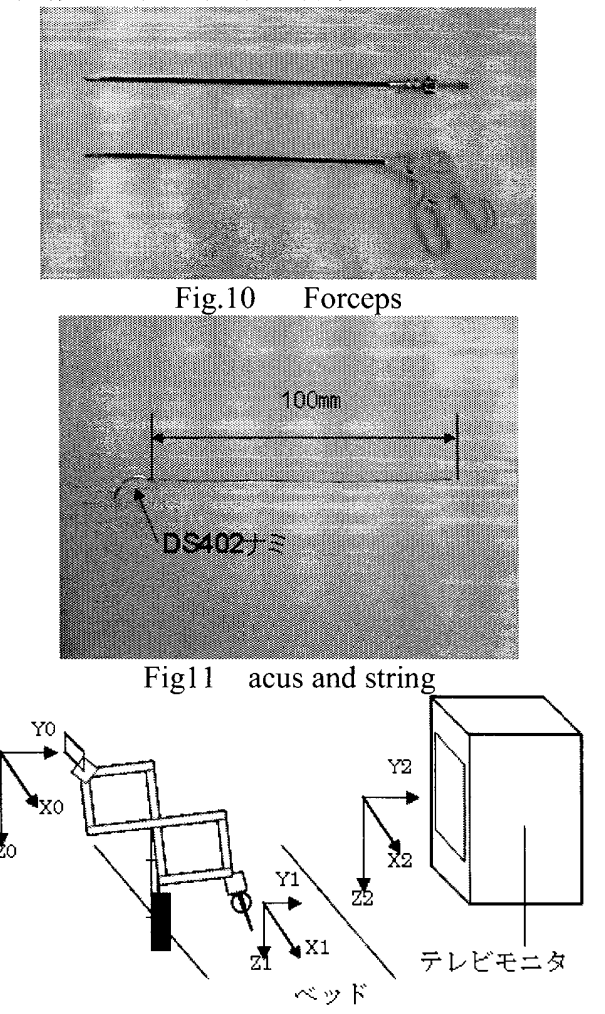

Fig.12 General coordinates and Machine device
(縫合作業)

針を右から左に刺し，結ぶ動作を図 19 の手順に従い，要し た時間を計測する。結び作業同様一人三回ずつ行う。

通常条件と作業軸条件では縫う作業, 結䅨作業, 縫合作業 を行い, 立体視条件では結紮作業, 縫合作業のみの実験とす る.

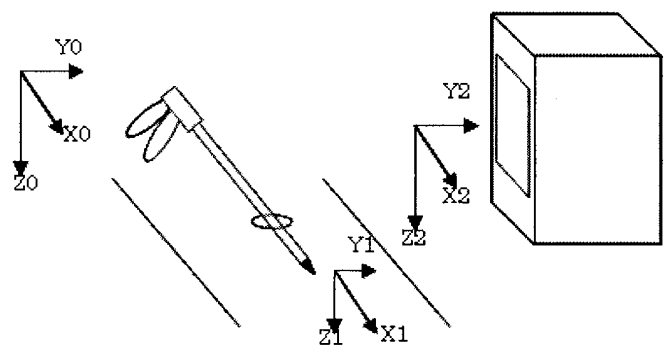

Fig.13 General coordinates and forceps

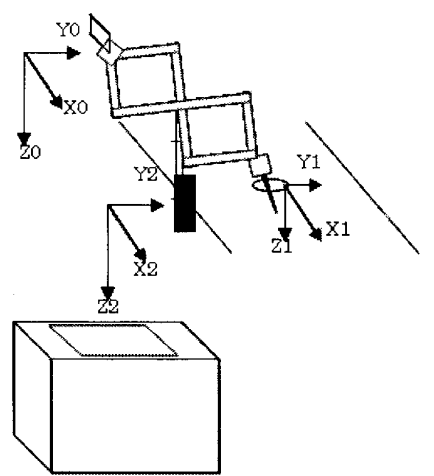

Fig. 14 Coincidence coordinates and Machine device

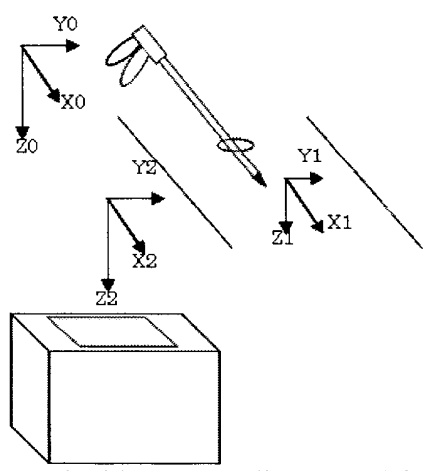

Fig. 15 Coincidence coordinates and forceps

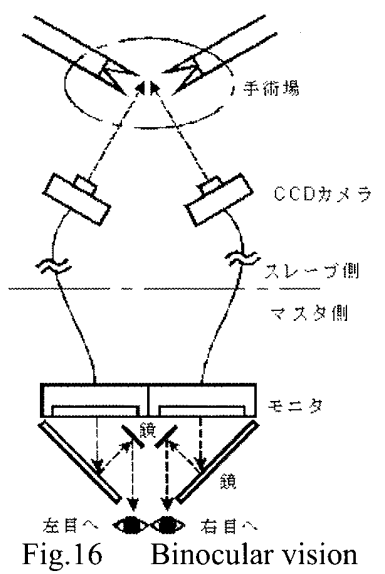




\section{3 実験結果 ·考察}

実験結果は表1，2に示す．結果は被験者の平均作業時間で ある. 縫う作業を条件別で比較すると， $6 \mathrm{~mm}$ 幅平均作業時間 と $2 \mathrm{~mm}$ 幅平均作業時間では両方ともシステムの使用する場合 の通常条件が最も作業時間が早い結果となった. しかし 6 m 幅と $2 \mathrm{~mm}$ 幅での標準偏差を比較するとシステムの使用する場 合の作業軸条件が最も小さい結果となった. 標準偏差が小さ いので被験者の作業時間のばらつきが小さく, システムの使 用に適した条件であったと考えられる. また平均作業時間が 結果に結びつかなかった原因は, 操作座標と視座標を一致さ せるため, テレビモニタを足元に置いたことで, マスター部 とテレビモニタが重なってしまい見えにくい状況が生じ, 結 果に影響したと考えられる. 結紮作業は条件別で比較すると 同じ条件であればシステムを使用した場合の方が平均作業時 間を短縮させた。これは糸を巻きつける動作が逆運動操作で 難しいために, システムの使用することで容易にできたとい える. システムを使用した場合では，立体視条件，作業軸条 件，通常条件の順に早い結果となった。標準偏差を見ると， 結柇作業は立体視条件が適した条件と思われる。これは針と 系, そしてピンセットの位置関係を確認ができるため, 迷わ ずに作業ができたためと考える.

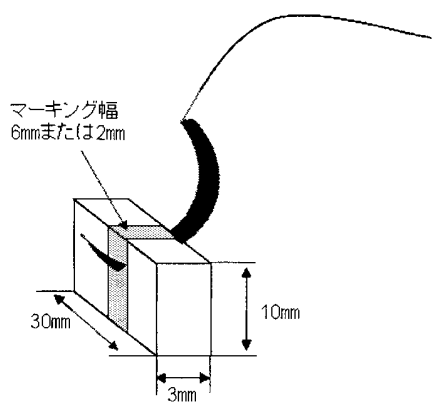

Fig. 17 Object
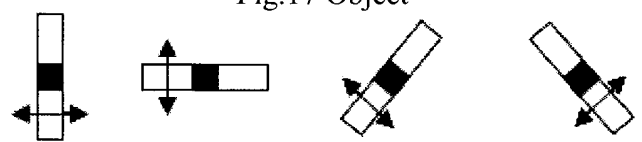

Fig.18 Direction for suture
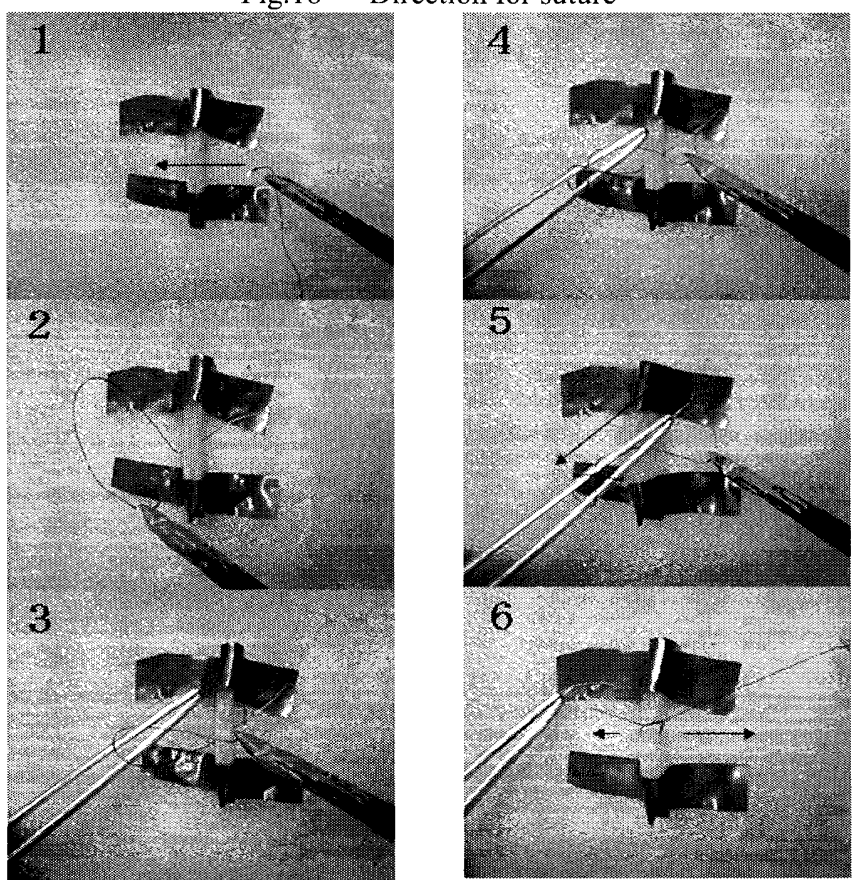

Fig.19 Legations process
そして縫合作業は結柇作業同様，同じ条件ではシステムを 使用した方が平均作業時間を短縮する結果となった。これは 縫う作業での時間よりも結染作業の時間が大きく影響したた めと考えられる。つまり標準偏差もその影響から立体視が小 さくなったといえる.

以上のことより，システムの使用で普通鉗子よりも作業時 間は短縮可能で操作の間違いが生じなくなった。さらに, 縫 う作業と結柇作業の最適な条件を見つけると, 操作座標と視 座標が一致した立体視を行えば，システムの使用で作業時間 の短縮が可能である.

\section{6. 結言}

本研究では腹腔鏡下外科手術において, 逆運動操作問題を 解消するシステムを開発した。システムを使用することで, 操作座標と作業座標が一致し, 逆運動操作問題を解消できた. またシステムの使用では鉗子の十分な作業空間が確認でき, 把持力も先端で最大 $12.2 \mathrm{~N}$ という結果が得られ，針や系を把持 するのに十分であった。

\section{7. 参考文献}

[1] Mitchell J.H. Lum1， Denny Trimble2， Jacob Rosen1, Kenneth Fodero II1, H. Hawkeye King1 , Ganesh Sankaranarayanan1, Jesse Dosher1, Rainer Leuschke1, Brandon Martin-Anderson1, Mika N. Sinanan3, Blake Hannaford I Multidisciplinary Approach for Developing a NewMinimally Invasive Surgical Robotic System BioRob 2006- The first IEEE / RAS-EMBS International Conference on Biomedical Robotics and Biomechatronics Pisa, Tuscany, Italy, February 20-22, 2006

[2] 藤原正寛 岩手大学修士論文 腹腔鏡下外 科手術における術具逆運動問題の一提案 2007

Table.1 Experimental result of suture

\begin{tabular}{|c|c|c|c|c|c|}
\hline \multirow{2}{*}{ 方向性 } & \multirow{2}{*}{ マーキング幅 } & \multicolumn{2}{|c|}{ 普通鉗子 } & \multicolumn{2}{|c|}{ システム } \\
\hline & & 通常条件 [sec] & 作業軸条件 [se & 通常条件 [sec] & 作業軸㳿件 [æec \\
\hline \multirow{2}{*}{$\leftarrow$} & $6 \mathrm{~mm}$ & 28.51 & 18.24 & 13.54 & \begin{tabular}{|r}
22.59 \\
\end{tabular} \\
\hline & $2 \mathrm{~mm}$ & 19.22 & 16.84 & 11.76 & 24.18 \\
\hline \multirow{2}{*}{$\rightarrow$} & $6 \mathrm{~mm}$ & 21.28 & 23.66 & 15.73 & 2069 \\
\hline & $2 \mathrm{~mm}$ & 25.56 & 27.68 & 14.47 & 26.81 \\
\hline \multirow{2}{*}{$\uparrow$} & $6 \mathrm{~mm}$ & 21.08 & 19.47 & 26.09 & 16.45 \\
\hline & $2 \mathrm{~mm}$ & 23.39 & 19.32 & 18.17 & 18.20 \\
\hline \multirow{2}{*}{$\downarrow$} & $6 \mathrm{~mm}$ & 2006 & 19.92 & 13.63 & 15.48 \\
\hline & $2 \mathrm{~mm}$ & 1978 & 17.31 & 23.82 & 22.11 \\
\hline \multirow{2}{*}{$\pi$} & $6 \mathrm{~mm}$ & 14.50 & 20.52 & 14.17 & 17.20 \\
\hline & $2 \mathrm{~mm}$ & 21.84 & 17.42 & 18.30 & 21.83 \\
\hline \multirow{2}{*}{$\swarrow$} & $6 \mathrm{~mm}$ & 25.93 & 19.15 & 13.55 & 20.45 \\
\hline & $2 \mathrm{~mm}$ & 28.37 & 24.99 & 18.56 & 21.61 \\
\hline \multirow{2}{*}{$k$} & $6 \mathrm{~mm}$ & 17.67 & 12.79 & 11.06 & 14.41 \\
\hline & $2 \mathrm{~mm}$ & 22.07 & 18.25 & 23.81 & 23.24 \\
\hline \multirow{2}{*}{ \pm} & $6 \mathrm{~mm}$ & 26.07 & 22.20 & 14.31 & 18.51 \\
\hline & $2 \mathrm{~mm}$ & 15.35 & 17.58 & 18.58 & 16.27 \\
\hline \multirow{2}{*}{$6 \mathrm{~mm}$} & 平均 & 21.89 & 19.49 & 15.26 & 18.22 \\
\hline & 徱集偏差 & 4.70 & 3.22 & 4.56 & 2.84 \\
\hline \multirow{2}{*}{$2 \mathrm{~mm}$} & 平均 & 21.95 & 19.92 & 18.43 & 21.78 \\
\hline & 瘭準偏差 & 4.00 & 4.09 & 4.11 & 3.31 \\
\hline
\end{tabular}

Table.2 Experimental result of knot working

\begin{tabular}{|c|c|c|c|c|c|c|}
\hline \multirow{2}{*}{ 結愁 } & \multicolumn{3}{|c|}{ 普通翻子 } & \multirow{2}{*}{\multicolumn{3}{|c|}{ システム }} \\
\hline & 通常条件[sec] & 作業軸条件[sec] & 㡴体視条件 [sec] $]$ & & & \\
\hline 平均 & 21.73 & 12.19 & 10.76 & 14.46 & 9.81 & 6.89 \\
\hline 摽準偏差 & 4.32 & 3.12 & 4.75 & 5.95 & 3.59 & 1.40 \\
\hline 推合 & \multicolumn{3}{|c|}{ 晋通种子 } & \multicolumn{3}{|c|}{ णХ的 } \\
\hline & 通常条件 [sec] & 作業軸条件 [sec] & 立体視桑件 $[\mathrm{sec}$ & 通常条件 $[$ s] & 作業軸条件[sec] & 应体視条件[sec \\
\hline 平均 & 63.80 & 45.05 & 45.18 & 45.83 & 4078 & 36.98 \\
\hline 摽準偏差 & 32.29 & 15.93 & 15.94 & 8.69 & 1002 & 6.95 \\
\hline
\end{tabular}

